\title{
Model of adaptable production planning and control
}

\author{
Borislav Gordic \\ MIRAKO Co., Draskoviceva 57, Zagreb, University NORTH - University Center Varazdin, Department of Logistic, Varazdin, Croatia
}

\section{Email address:}

gordicb@yahoo.com

\section{To cite this article:}

Borislav Gordic. Model of Adaptable Production Planning and Control. Science Journal of Business and Management. Vol. 2, No. 5, 2014, pp. 153-162. doi: 10.11648/j.sjbm.20140205.16

\begin{abstract}
In research of a model of production planning and control that can adapt to changes, disturbances and risks a model of adaptable optimization, called discrete corrective dynamizing optimization, was created. The model is created on the basis of dynamic programming to which is added the model of corrective optimization by simulation with the criteria defined in the initial and corrective part of the optimization. The effectiveness of a model of discrete corrective dynamizing programming was tested in relation to three other models of production programming. Testing has shown that the smallest deviations of the product quantities were obtained by applying the model of discrete corrective dynamizing optimization. It was also shown that the difference in the realized profit rate as the optimization criterion in relation to actual results was negligible in all testing conditions-variants. This is also a proof that with the use of corrective optimization a possible optimum can be achieved, with maximum adjustment to changes.
\end{abstract}

Keywords: Discrete Corrective Dynamizing Programming, Production Adaptability, Software for Simulation, Profit Rate, Flexible Planning and Production Control, Make-to-Stock and Make-to-Order Batch Production

\section{Introduction}

Most of the research on operational planning and production control in the past 10 years has been dealing with the research of this area in specific cases or in cases of uncertainty. In doing so, more and more emphasis has been put on the need for a more significant heuristic approach for which the following models for operational planning and production control are most often proposed:

a. application of heuristic methods in combined make-tostock and make-to-order production ([1], [2])

b. model of capacity planning for a longer period of time for the sake of greater production flexibility and faster product delivery of products ([3])

c. model of planning in conditions of instability, with the obligation to meet deadlines ([4])

d. simulation as a model of production optimization in cases of make-to-order production and in conditions of instability ([5], [6], [7], [8], [9])

e. optimization in make-to-order production with selection of orders according to deadlines and capacities ([10])

f. production plans optimization model with the application of the simulation method to include additional orders into the plans and to synchronize the sales and production ([11])
It can be also stated that there is virtually no operational planning and production control model that can be generalized for a larger number of conditions and different production types and it is therefore very difficult to compare precisely the effectiveness of actual models of operational planning and production control.

Therefore, it is realistic to expect that due to the incresing presence of uncertainty and changes in the environment, the heuristic approach will be even more present in designing future models, which means that the increasing part of the solutions will be based on experience. Then at the same time arises the question about determining the exact optimum and is therefore more certain that the models which would provide approximate optimums in particular conditions will be created and that the methods used will provide solutions that will be adjusted as much as possible to changes in the environment and in the production system itself.

Although the intention is to develop a model that will find the optimum solution, this is sometimes very difficult and therefore it is necessary to get satisfied with some other acceptable solution which need not necessarily be optimal but satisfies all problem conditions. Very often, the approximate calculation methods have a strong mathematical background that indicates their reliability regardless of the input data. At the same time, they provide convergence 
evaluation and thus it is always possible to know how close to (or far from) the optimal solution it is.

In the author's research of the possibilities for the development of flexible planing and production control, it has been shown that the selection of the model and optimization of the process of operational planning and production control significantly influences the successfulness and adaptability of the production system and business operation in the conditions of dynamic changes in the environment and in production system itself. In the present research, a corrective optimization model named discrete corrective dynamizing optimization has been tested on a practical example and in this way the above mentioned results of the previous research were confirmed once again.

\section{Dynamizing Programming}

Dynamic programming as part of mathematical programming is a methods and techniques of optimization of solutions in which time is an important factor and it requires management process which is gradual and implemented through several periods, in several phases, so that the optimization of planning for a larger number of periodphases is conducted throught several steps which precedethe final goal

If the indicator $\Phi$ is taken as the criteria of dynamic programming of production system $S$ for a period $T$ and if the system is managed over time through the solution $U$, there is a problem of choosing solutions $U t$ by periods $t$ in order to achieve maximum or minimum of $\Phi$. In the case of planning it means the setting of plans $P 1, P 2, \ldots P k$ for the time period $T$, which consists of m-periods-phases. If $x_{i j}$ is solution for the $i$-period and plan $P i$, then the vector in equation (1) is the solution $\mathrm{Pi}$.

$$
\overrightarrow{X_{(\imath)}}=\left(x_{i 1}, x_{i 2}, \ldots \ldots x_{i k}\right)
$$

Vectors $\overrightarrow{X_{1}}, \overrightarrow{X_{2}}, \ldots . \overrightarrow{X_{k}}$ is corresponding to the set of solutions $U_{1}, U_{2}, \ldots U_{k}$ define the function $\Phi$ which has to be maximized or minimized by the expression (2)

$$
\Phi=\Phi\left(U_{1}, U_{2}, \ldots U_{k}\right)
$$

In essence, dynamic programming is a phased management, or solving the task whereby in each periodphase appropriate decisions need to be made. They do not have to be optimal at every phase but the aim is on a comprehensive optimality in total treated period. The optimality of the last step, as the last phase in the decisionmaking process, is based on the penultimate decision, that one on the previous etc., representing a conditioned optimum.

Nonetheless, the problem lies in the lack of an appropriate algorithm for dynamic programming which the scientists have not been able to find in the past few decades, so in esence the practical application of dynamic programming to certain procedures is reduced to linear programming.

One way to obtain dynamics in production plans programming in the sense of adaptability is to use sliding, flexible planning and control using the linear programming method and such a model can be called dynamizing programming which schematic presentation is given in Figure 1.

Regarding to the model of dinamizing programming, in the case when the basic plan is a monthly plan and the first higher level plan is a quarterly plan, optimization of three monthly plans of one quarter $P_{i}, P_{i+1}$ i $P_{i+2}$ is performed by linear programming in accordance with the upper and lower limits of demand $Q_{i j}^{g}$ i $Q_{i j}^{d}, Q_{i+1, j}^{g}$ i $Q_{i+1, j}^{d}$ te $Q_{i+2, j}^{g}$ i $Q_{i+2, j}^{d}$, as well as the

limitations of other resources relevant to programming and optimization of production plans. With expiry of the period of higher level plan corrections (Tk)v reprogramming has to be carried out for three plans for the next three parts of quarters part $R_{i+1}, R_{i+2}$ and $R_{i+3}$ with corrected limits of demand $\left(Q_{i+1, j}^{g}\right)^{\prime}$ and $\left(Q_{i+1, j}^{d}\right)^{\prime} ;\left(Q_{i+2, j}^{g}\right)^{\prime}$ and $\left(Q_{i+2, j}^{d}\right)^{\prime}$ and $\left(Q_{i+3, j}^{g}\right)^{\prime}$ and $\left(Q_{i+3, j}^{d}\right)^{\prime}$. Correction of these borders is made to expected additional orders received in previous periods $Q d_{i j}$, $Q d_{i-1, j}$, etc.., in line with other available resources. Analogously, it is handled when orders are canceled or due to disruption in the availability of resources, the plans of realization are reduced.

When the model of dinamizing programming wants to include the optimal solving of the situations of changes and disorders according to different stage of the period for which the best solution is given previously, either treated selected planning period from the moment of decision-making about the same or to determine the solution change in the current plan by simulation.

If the correction of the operational plan $O P_{i}$ is done with expiry of a period of correction (Tk)o, then it will be determined which part of the unexpected additional orders $Q v_{i j}$ could be realized in the current operating period by simulation, and thereby corrected operational plan $\left(O P_{i}\right)^{\prime}$ is obtained.

In case of new optimization of plans for any significant changes or disorders for selected period through dynamizing programming, it is very likely that the following problems would arise:

a. changes in the order of realization of a series of orders with fixed delivery time

b. changes in plans of procurement of raw materials

c. re-allocation of technological operations in the process of production for the planned products in the course of their production

All this can significantly impede the realization of the production and cause additional costs and activities, particularly in the planning and control, and it needs election and forming of a model that may be applicable in a number of types and conditions of production.

Such a model of corrective optimization, by which the plans could be corrected with the application of simulation and the flexible-sliding process of planning and control is called discrete corrective dynamizing optimization.

However, before designing a model of discrete corrective dynamizing optimization it is necessary to establish criteria 
and measures for determination of the optimal correction of plan that will on one hand be in accordance with existing, selected criteria for dynamizing programming and on the other, depending to when and which optimal plan correction is possible.

The correction that is selected as the most favourable, optimal correction of an operational plan is the one at which the biggest difference in revenue and profit increase will be achieved in relation to the additional costs of operational planning and production control, as follows according to expression (3)

$$
\mathrm{EK}=\mathrm{IPP}-\mathrm{PT}
$$

where: EK - plan correction efficiency

PT - costs of changes
IPP - index of revenue change IP and profit change IF, according to expression (4)

$$
\mathrm{IPP}=\mathrm{IP} \cdot \mathrm{IF}
$$

Cost of changes PT is taken in the scale of decimal expression of the percentage of the cost change in relation to the costs in the existing plan, and the revenue change IP and profit change IF, as well as their product according to expression (4) are expressed as an index, i.e. as decimal expression of percentage of change increased by 1 , and thus it is always valid that IPP $>$ PT, for ease of operation.

Index of revenue and profit change IPP indicates how much the efficiency of the initial, basic plan can be increased as an indicator of adaptability and flexibility of the production system to market changes.

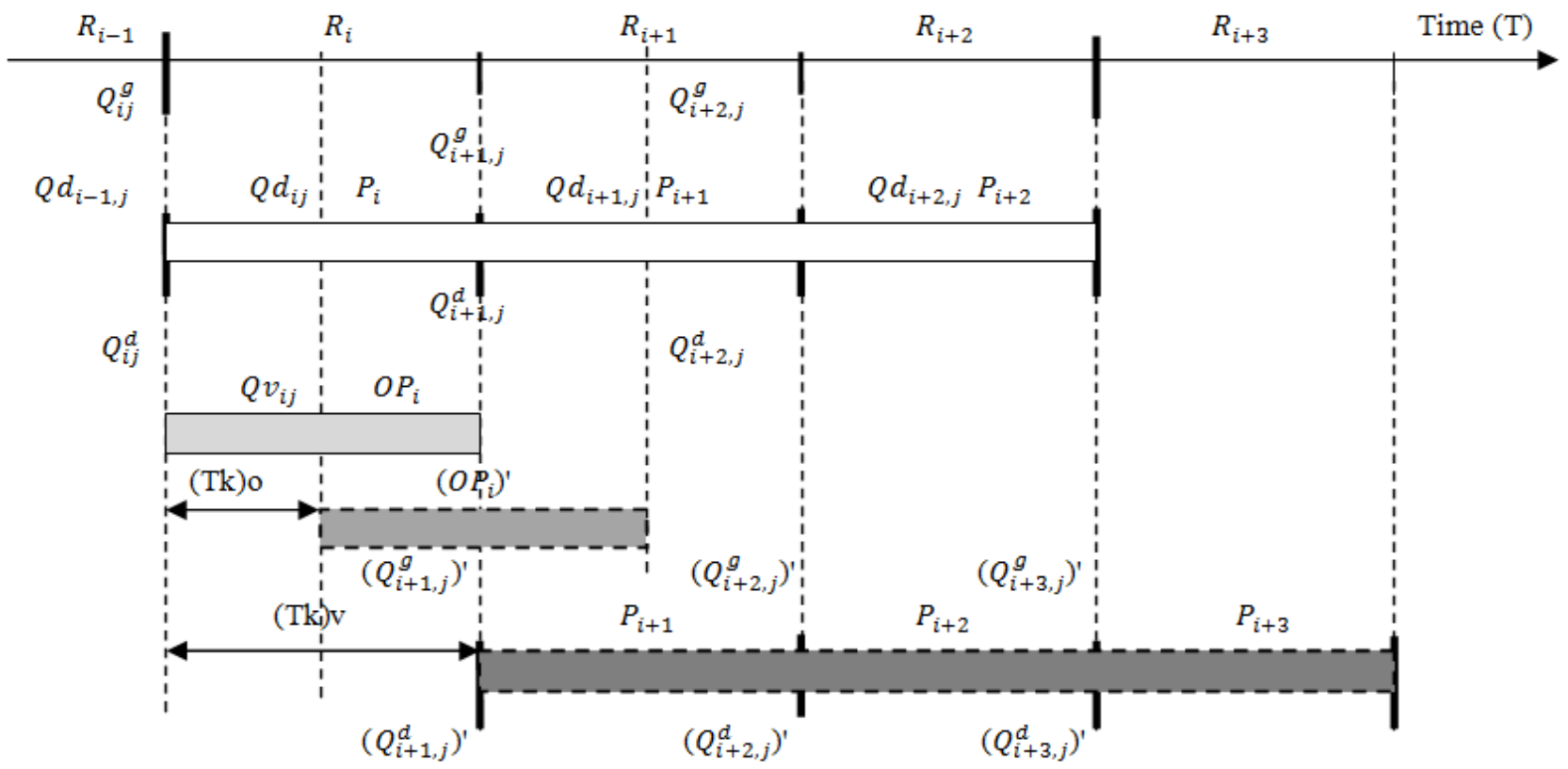

Figure 1. Shematic presentation of the model of dinamizing programming. (B. Gordic, 2013)

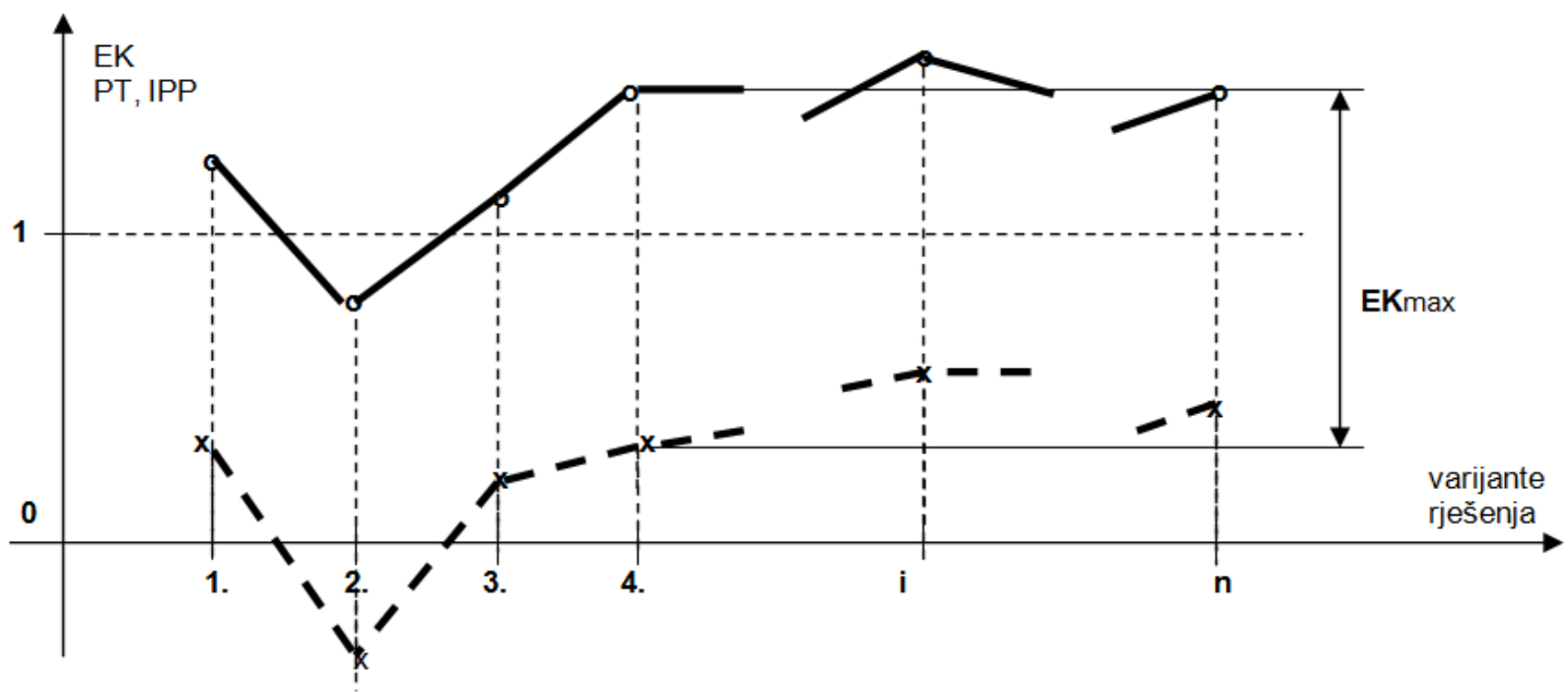

Figure 2. Posibilities and determination of the optimal variant of basic plan correction. (B. Gordic, 2013) 
In case of a large range of products have to be made bigger number of possible variants of corrected solutions in the operational plans and by the previously mentioned criteria will be determined the best possible correction of plan. Under the possible variants of plan corrections are involved solutions for which exist or can immediately be provided necessary resources and where will be possible to send new orders in manufacturing with eventual changes of operating places and scheduling of orders in work within their deadlines only.

It is logical that each production system wants to use each advantage of increasing demand, in terms of improving business performance and in terms of satisfying the needs of the market. At the same time it is trying to achieve aims with minimal increase of the planning and control costs, which includes many items such as the direct costs of planning and control, costs of inventories of products and raw materials, cost of additional capacity and labor, etc.

However, the index of changes in revenues and profits IPP can take on values less than 1 , such as changes in the cost PT may have a negative value because the changes and disorders in the environment and the treated system can be with positive or negative character, as follows:

a. increasing market demand, and revenue growth, with increasing or decreasing profitability and lower or bigger increase in the cost of planning and control

b. reducing the demand or canceling orders of products or disorders in the production

c. reducing the demand or canceling the orders of products or disorders in the production and procurement of materials with decline in revenues, change of profitability and cost of planning

Changes and disorders are collected and processed in each period of adjustment (Tk)i of basic plan and its checks and corrections are done properly, for each period of correction.

For this purpose it uses the method of simualtion to choose solution of plan correction in which the effeciency of correction EK is maximal between of all realy possible variants, as it is shown in Figure 2. As the variants of the correction of starting basic plan shall be taken only ones that can be implemented in the period of following corrected basic plan. Therefore, changes in the environment that can not be treated in this period are transferred for treatment in the next period of correction or leave for consideration in the preparation of the next initial basic plan or corrections of first higher level starting plan.

Discrete corrective dynamizing optimization allows to production system to adapt maximally in situation with changes, disorders and risks in the environment and in the system in such a way that in case of positive change, or a rise in demand of finished products, increase own successfulness of production UP (1). In the case of negative changes and disorders - delay in supply of materials, equipment failure, etc.., it will minimize deviations from the previously determined optimum performance of production UP with minimal disturbation of the production rhythm.
If the information about the change has a negative character, it will be taken into treatment at the first following correction of the current plan and if its character is positive, the information will be classified in the appropriate period of basic plan - monthly period. The actuality of positive information is determined by the required, planned deadline for its realization in production. Thus classified information about the changes will be discussed as follows:

a. all actual information from the first shortest correction period Tk will be used for the first correction of the basic plan KPMP1 'which will be optimized by simulation

b. for the performing of optimization of the first corrected basic plan KPMP1 'will be determined its possible alternatives and between them will be choosen optimal solution

c. other informations about the changes will be treated to the same way in each next correction of first higher level plan, according to their relevance

d. information about changes that have been going on for period of the second basic plan will be treated within correction of the first higher level plan, in this case quarter plan, KPKP1'

e. corrected first higher level plan, as well as other higher level plans, will be determined by its parts using the dinamizing programming on the previously described way

Although there was not changes in second week, for example, it is necessary to make another correction of the first monthly plan KPMP1' due to making the realization of second part of the initial monthly plan in the next week which ensures the continuity of the production realization and management.

Correction of the first higher level plan will be determined by dynamizing programming and at the same time its 3 partsstages will be determined as the basic plans for the next 3 months (quarterly plans), as part of the optimal solution for the following quarter. In the same way the next higher level plan by dynamizing programming will be optimized.

Nonetheless, it is possible that in the case of a large number of bigger changes and corrections of the first higher level plan it will be necessary to optimize plan by simulation if it is assessed that dynamizing programming will significantly impair the plan of production of the already defined orders or orders in work due to actual significant changes. The application of discrete corrective dinamizing optimization allows the flexibility of planning and control because in each group of optimal starting solutions OPi periodically joins realistically possible part of the changes $\mathrm{Pij}$ and in that way to get the corrected optimal solution OPk.

The resulting corrected optimums may be slightly smaller or larger than the initial optimum, depending on the character and actuality of the group of changes $\mathrm{Pij}$, but with certainty is achieved more flexibility of the production system to the changing environment and to the changing within the production system.

This applies to the case for correction of the basic plan by simulation with the criteria $\Phi=\Phi(\mathrm{EK}) \max$ where EK=IPP- 
PT (3), and in case of corrections of higher level plan through dynamizing programming on the criteria $\Phi=\Phi(\mathrm{UP}) \mathrm{max}$, where in the UP=IK $\cdot \mathrm{PF}(5)$.

The process of planning and control that uses discrete corrective dynamizing optimization, which are treated with due-date changes, is possible:

1. Responding to changes within the short term, alonside with searching the most favourable corrected solutions

2. Correction of plans is made timely, on the basis of possibilities in which are included current changes

3. Timely implementation of plans

4. Better preparation of the production system and other process for the next period (procurement of materials, additional capacity, additional work etc..)

Given that it is a model of adaptive planning and control, success will substantially depend not only to the type and mode of production but also on the degree of uncertainty and changes.

\section{Selection of Models for Testing}

The method of discrete corrective dynamizing optimization represents a synergy of continuous, periodic adjustment of operational plans and the information about orders for products arriving in the current period that are to be delivered in the forthcoming basic operational planning period. Then, the same are being corrected in relation to the orders received in the current period whose delivery terms are in the same period.

For the testing of the method of discrete corrective dynamizing optimization the data from practical examples were taken. These data cover several groups of products for the period of the first 6 characteristic months of the year. Testing was done in a way that the results of the production plans optimization were compared with the really achieved results for the selected practical example. For comparison with these results, the following models of production plans optimization were selected:

A. Linear programming

B. Dynamizing programming

C. Linear programming with corrective optimization by simulation

D. Discrete corrective dynamizing programming.

Considering the available possibilities for testing, the models B, C and D were somewhat simplified in a way that they all as a basis had a simplex method of linear programming for which the necessary software was available. By changing part of the parameters the simplex method was adjusted to other listed models in an appropriate way and in $\mathrm{C}$ and $\mathrm{D}$ models a simplified technique of simulation was added.

When applying linear programming by simplex method, as model A, for the upper and lower limits of product demand the data about the dissipation of realization on the market were taken, thus as the upper limit for each considered month the maximum achieved realization of each product was taken, and as the lower limit the lowest achieved realization of that product in the month was taken.

Simplified model of dynamizing programming, as model $\mathrm{B}$, was made in such a way that a part of the expected additional orders, as an expression of changes in the environment, was included in determination of the upper and lower limits of product demand in each month. In this way a part of the orders that are received in the current month for the first part of the current month were included, while the additional orders for the deliveries in the second part of the current month were excluded from the treatment. Generating the part of additional orders, the correction of the upper and lower limits of product demand was made for some $25-50 \%$ of the total share of additional orders for each product in each month and then linear programming by simplex method was applied in these new conditions.

As the third, $\mathrm{C}$ model for testing, the simplified model of linear programming with corrective optimization by simulation was taken. According to this model the initial optimally programmed plan is modified on the basis of the changes - additional orders during the current month using the method of simulation.

In this model the initial plan is the solution obtained by the above listed A model of linear programming using the simplex method and the corrections of the current plan were made for all extra orders that had to be realized during the current operational plan.

Discrete corrective dynamizing programming, as model D, was also somewhat simplified for this testing in a way that part of the expected additional orders was included into the current operational plan based on the application of flexible planning (by periodic repetition) and the other part, approximatively as well as the total share of additional orders for each product in each month. Thus, unexpected additional orders would be the basis for the correction of the current plan using the method of simulation. It was a combination of dynamizing programming (B model for testing) and corrective optimization using the method of simulation.

In all 4 tested models whose results were compared with the results achieved in the example from practice used in the considered research, the optimization criterion was the successfulness of production-business operation UP according to expression (5)

$$
\mathrm{UP}=\mathrm{IK} \cdot \mathrm{PF}
$$

where: IK - capacity utilization (measured in the decimal expression of percentage)

$\mathrm{PF}$ - profit rate (measured in the decimal expression of percentage)

For testing the selected models in relation to the results from the practical example the criterion of adaptibility PG was used according to expression (6)

$$
\mathrm{PG}=\Sigma \Delta \mathrm{Qi} / \mathrm{p}
$$

where: $\Sigma \Delta$ Qi - difference between planned and realized quantities in the decimal expression of percentage 
$\mathrm{p}$ - number of treated product groups

where the adaptibility function $\Phi=\Phi(\mathrm{PG}) \mathrm{min}$

Correction of the operational plans in the tested models 3 and 4 was not optimized according to the criterion of maximization but was made according to the possible, most favourable solutions using the criterion of of the smallest profit rate loss GP according to expression (7)

$$
\mathrm{GP}=(1-\Delta \mathrm{PF})
$$

Because of the comparison of the tested optimization models with the real results from the practical example regarding the criterion of adaptability, the available capacity was taken as a constant. At the same time, the criterion of retaining the same profit rate was used and the main aim was to achieve greater adaptability of plans in relation to changes and requirements from the environment-market.

Corrections of products in the plans were made according to the indicators of cost effectivness $K S_{i}(8)$ and correction $K p_{i j}(9)$

$$
\begin{aligned}
K S_{i} & =Z K_{i} \cdot P S_{i} \\
K p_{i j} & =Z K_{i j} / P S_{i j}
\end{aligned}
$$

where: ZK - share in taking of capacity

PS - profit rate in such a way that the additional orders were included in the plan on the account of the products from the plan for which there were no additional orders, according to the criterion $\left(K S_{i}\right) \max$ and $\left(K p_{i j}\right) \max$.

\section{Test Conditions}

Testing of the 4 optimization models was performed on two practical examples - production of dishes $(\mathrm{Pi})$ and production of automotive glass (Ai) in which an average realization on the market $Q_{i j}$ was achieved within the upper $Q_{i j}^{g}$ and lower limits $Q_{i j}^{d}$. In the first example there were products arranged in groups from $\mathrm{P} 1$ to $\mathrm{P} 6$, and in the second one products from A1 to A10, with the data for the first 6 months of the year, in the past four years. To create the software, MATLAB system was used and the software was identical for both practical examples.

As mentioned in the described practical examples, there were additional orders $\mathrm{Qd}_{\mathrm{ij}}$ for the current operational planning period, which covered 1 month, and they of the average size. Also, with a certain probability unexpected additional orders $Q v_{i j}$ occurred in the current operational period, with delivery terms in the same period and in the average size.

For testing and and comparison of the selected models of optimal production programming the data about the production of the selected practical examples that were necessary for the application of the optimization methods were also used. They are presented in Table 1, whereas in Table 2 the capacity limitations per months are given for the

\begin{tabular}{|c|c|c|c|c|c|c|c|c|c|c|}
\hline \multirow{2}{*}{$\begin{array}{l}\text { Characteristics } \\
\text { I. Tableware production }\end{array}$} & \multicolumn{10}{|c|}{ Products / Indicators per products } \\
\hline & \multicolumn{2}{|l|}{$\mathrm{P} 1$} & $\mathrm{P} 2$ & \multicolumn{2}{|l|}{ P3 } & P4 & \multicolumn{2}{|c|}{ P5 } & \multicolumn{2}{|l|}{ P6 } \\
\hline 1. share in capacity of 10000 pcs. & \multicolumn{2}{|l|}{0.080} & 0.060 & \multicolumn{2}{|l|}{0.030} & 0.030 & \multicolumn{2}{|c|}{0.040} & \multicolumn{2}{|c|}{0.050} \\
\hline 2. profit rate $P F_{i}$ & \multicolumn{2}{|l|}{0.140} & 0.180 & 0.100 & & 0.110 & \multicolumn{2}{|c|}{0.120} & \multicolumn{2}{|c|}{0.080} \\
\hline II. Car glass production & A1 & A2 & $\mathrm{A} 3$ & A4 & A5 & A6 & A7 & A8 & A9 & A10 \\
\hline 1. share in capacity of $100 \mathrm{pcs}$. & 0.028 & 0.030 & 0.035 & 0.028 & 0.024 & 0.030 & 0.027 & 0.024 & 0.020 & 0.023 \\
\hline 2. profit rate $P F_{i}$ & 0.110 & 0.120 & 0.100 & 0.090 & 0.080 & 0.100 & 0.090 & 0.070 & 0.070 & 0.080 \\
\hline
\end{tabular}
sake of comparison of the selected optimization methods.

Table 1. Production characteristics for the used practical examples. (B. Gordic, 2013)

Table 2. Capacity limitations per months. (B. Gordic, 2013)

\begin{tabular}{lllllll}
\hline & \multicolumn{2}{l}{ M O N T H S } & & & & \\
\cline { 2 - 6 } Capacity limitations per months & I. & II. & III. & IV. & V. \\
\hline 1. Tableware production, $\mathrm{IK}_{\mathrm{p}}$ & 0.75 & 0.86 & 0.92 & 0.80 & 0.70 \\
2. Car glass production, $\mathrm{IK}_{\mathrm{a}}$ & 0.48 & 0.51 & 0.53 & 0.57 & 0.54 \\
\hline
\end{tabular}

Shematic presentation of the base working documents and procedures for tested optimization models is shown in Figure 3.

Preparation of the plans using the simplex method of linear programming (A) was made in such a way that the range of realization in the market in the last 5 years with the lower $Q_{i j}^{d}$ and upper $Q_{i j}^{g}$ realization range was used as limitation of the quantity of products for the preparation of the operational plan $O P_{i}$, while the capacity limitations $\mathrm{IK}_{\mathrm{i}}$ per months were within the average values of the previous years. This procedure was repeated in each current period of the operational plan $R_{i}$ for the next period $R_{i+1}$.

Dynamizing linear programming (model $\mathrm{B}$ ) is actually a linear programming model that is partly dynamizing in a way that the operational plans are being corrected by means of flexible planning and control.

This is done in a way that the expected additional orders $Q d_{i j}$ from the previous period of the operational plan correction (Tk)o are included, which then reduces the lower and upper demand limitations in optimization according to 
the simplex method, and the corrected lower $\left(Q_{i j}^{d}\right)^{\prime}$ and upper $\left(Q_{i j}^{g}\right)^{\prime}$ limitations are calculated according to the following expressions

$$
\begin{gathered}
\left(Q_{i j}^{d}\right)^{\prime}=Q_{i j}^{d}+Q d_{i j} / 2 \\
\left(Q_{i j}^{g}\right)^{\prime}=Q_{i j}^{g}-Q d_{i j} / 2
\end{gathered}
$$

In doing so, all the expected additional orders from the previous operational planning periods $\left(R_{i-1}, R_{i-2}, \ldots\right)$ for the products that are to be made and delivered in the period $R_{i}$ are included in the additional customer orders $Q d_{i j}$. For these orders all the necessaty resources either exist or can be immediately provided.

Optimization of production plans by linear programming with correction by simulation (C) was done in such a way that the optimization solutions according to model A as starting solutions were corrected by simulation with additional quantities $\left(Q d_{i j}\right)^{\prime}$ as the sum of the quantities of unexpected additional orders for products $Q v_{i j}$ and thier expected additional quantities $Q d_{i j}$. Unexpected additional orders $Q v_{i j}$ for which necessary resources are available will be realized in the second part of the operational planning period $R_{i}$ and the remaining ones will become additional orders $Q d_{i j}$ in the next correction of the operational plan. For them it is necessary to provide necessary resources in the period $R_{i+1}$ of the next operational plan $O P_{i+1}$. This means that the corrections of the selected products by imitation are made for the total quantities $\left(Q d_{i j}\right)^{\prime}=Q d_{i j}+Q v_{i j}$.

Optimization of production plans using the simplified discrete corrective dynamizing programming (model D) was done in a way that the solutions of the optimization according to model B as starting solutions were corrected by simulation with the quantities of unexpected additional orders $Q v_{i j}$. In the production plans obtained by dynamizing linear programming and corrected by simulation (model D) the products for which additional orders were expected were not corrected because the quantities from the initial plan were at the upper limit of demand, and this was also applied in model C.

For greater credibility of model testing and evaluation of the efficiency of the model of discrete corrective dynamizing programming for both practical examples several case variants in the environment were tested by varying the values of the following parameters:

a. $\mathrm{X}$ - degree of uncertainty-risk in the environment

b. $\quad \mathrm{Y}-$ share of additional orders

c. $\mathrm{Z}$ - share of emergency orders

The degree of uncertainty $X$ as a form of risk represents the probability of deviation from the usual, time set minimal and maximal limits of product demand, i.e. difference between the upper $Q_{i j}^{g}$ and lower $Q_{i j}^{d}$ limits of demand. This difference will be greater if the percentage of make-to-order production is increased, i.e. if there is a growth of expected additional orders $Q d_{i j}$ and unexpected $Q v_{i j}$ additional orders. During optimization model testing, the variable $\mathrm{Xi}$ as the degree of uncertainty-risk asumed the values proportional to the share of expected and unexpected additional orders, in the range of $0-8 \%$, which is indicated by respective index of the variable $\mathrm{X}$.

Combinations-variants of cases for testing were obtained by combining the starting and multiplied values of additional $Q d_{i j}$ and emergency $Q v_{i j}$ orders, where: $\mathrm{Y} 1=Q d_{i 1}$, $\mathrm{Y} 2=2 Q d_{i 1}, \mathrm{Y} 3=3 Q d_{i 1}, \mathrm{Y} 4=4 Q d_{i 1}$, and also $\mathrm{Z1}=Q v_{i 1}$, $\mathrm{Z} 2=2 Q v_{i 1}, \mathrm{Z} 3=3 Q v_{i 1}, \mathrm{Z} 4=4 Q v_{i 1}$. In this way, 10 variantscases were obtained and were tested for each optimization model.

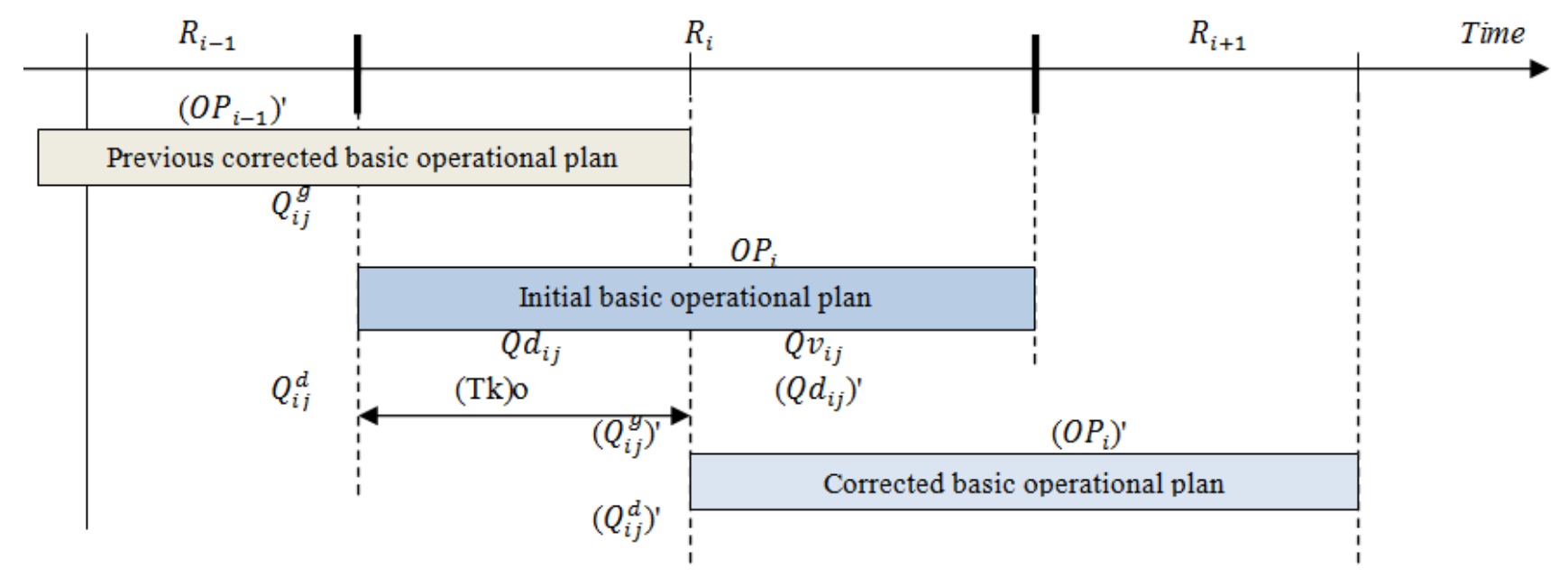

Figure 3. Shematic presentation of the base working documents and procedures for tested optimization models. (B. Gordic, 2013)

\section{Test Results}

For all tested models, including the intial practical example, the capacity limitations were the same and almost identical profit rates were realized. Difference in the results obtained by different optimization models can be seen in the way that the results obtained in the production plans for each running of the program with a different variant are compared with the actual realization from the practical example through the imbalance of quantities, as shown in Table 3, Table 4 and in Figure 4. 
Table 3. Optimization model test results for the example of dishes and automotive glass production. (B. Gordic, 2013)

\begin{tabular}{|c|c|c|c|c|c|c|c|c|}
\hline \multirow{3}{*}{ Test Variants } & \multicolumn{8}{|c|}{ Deviation in Quantity (\%) } \\
\hline & \multicolumn{2}{|c|}{ Model A } & \multicolumn{2}{|c|}{ Model B } & \multicolumn{2}{|c|}{ Model C } & \multicolumn{2}{|c|}{ Model D } \\
\hline & Dishes & A.Glass & Dishes & A.Glass & Dishes & A.Glass & Dishes & A.Glass \\
\hline 01. Variant X0Y1Z1 & 7,69 & 6,18 & 4,82 & 3,83 & 6,86 & 5,37 & 4,32 & 3,21 \\
\hline 02. Variant $\mathrm{X} 2 \mathrm{Y} 2 \mathrm{Z} 1$ & 9,37 & 7,42 & 4,40 & 2,84 & 8,57 & 6,84 & 3,95 & 2,56 \\
\hline 03. Variant X3Y1Z2 & 10,18 & 7,99 & 6,97 & 5,01 & 8,54 & 6,83 & 6,21 & 4,53 \\
\hline 04. Variant X4Y2Z2 & 11,00 & 8,54 & 4,58 & 2,91 & 9,50 & 7,09 & 4,24 & 2,71 \\
\hline 05. Variant $\mathrm{X} 4 \mathrm{Y} 3 \mathrm{Z} 1$ & 11,00 & 8,54 & 5,62 & 3,91 & 9,46 & 6,96 & 4,77 & 3,40 \\
\hline 06. Variant X4Y1Z3 & 11,00 & 8,54 & 8,20 & 6,27 & 9,16 & 6,92 & 7,34 & 5,76 \\
\hline 07. Variant X5Y3Z3 & 11,81 & 9,10 & 6,56 & 3,90 & 10,21 & 6,99 & 5,94 & 3,62 \\
\hline 08. Variant X5Y4Z2 & 11,81 & 9,66 & 6,21 & 3,97 & 11,19 & 8,15 & 5,94 & 3,64 \\
\hline 09. Variant X6Y2Z4 & 12,63 & 9,66 & 9,43 & 7,46 & 11,83 & 8,24 & 8,69 & 7,01 \\
\hline 10. Variant X8Y4Z4 & 14,25 & 10,78 & 7,97 & 5,26 & 12,84 & 9,24 & 7,46 & 4,80 \\
\hline
\end{tabular}

Table 4. The average realized profit $P F_{m}(\%)$ per optimization model and type of production. (B. Gordic, 2013)

\begin{tabular}{lll}
\hline & Dishes & Automotive glass \\
\hline Realized - actual realization $\mathrm{PF}_{\mathrm{O}}$ & 11,40 & 8,81 \\
A. - linear programming $\mathrm{PF}_{\mathrm{A}}$ & 11,52 & 8,90 \\
B. - dinamizing linear programming $\mathrm{PF}_{\mathrm{B}}$ & 11,47 & 8,83 \\
C. - linear programming with correction by simulation $\mathrm{PF}_{\mathrm{C}}$ & 11,42 & 8,77 \\
D. - discrete corrective dinamizing programming $\mathrm{PF}_{\mathrm{D}}$ & 11,42 & 8,77 \\
\hline
\end{tabular}

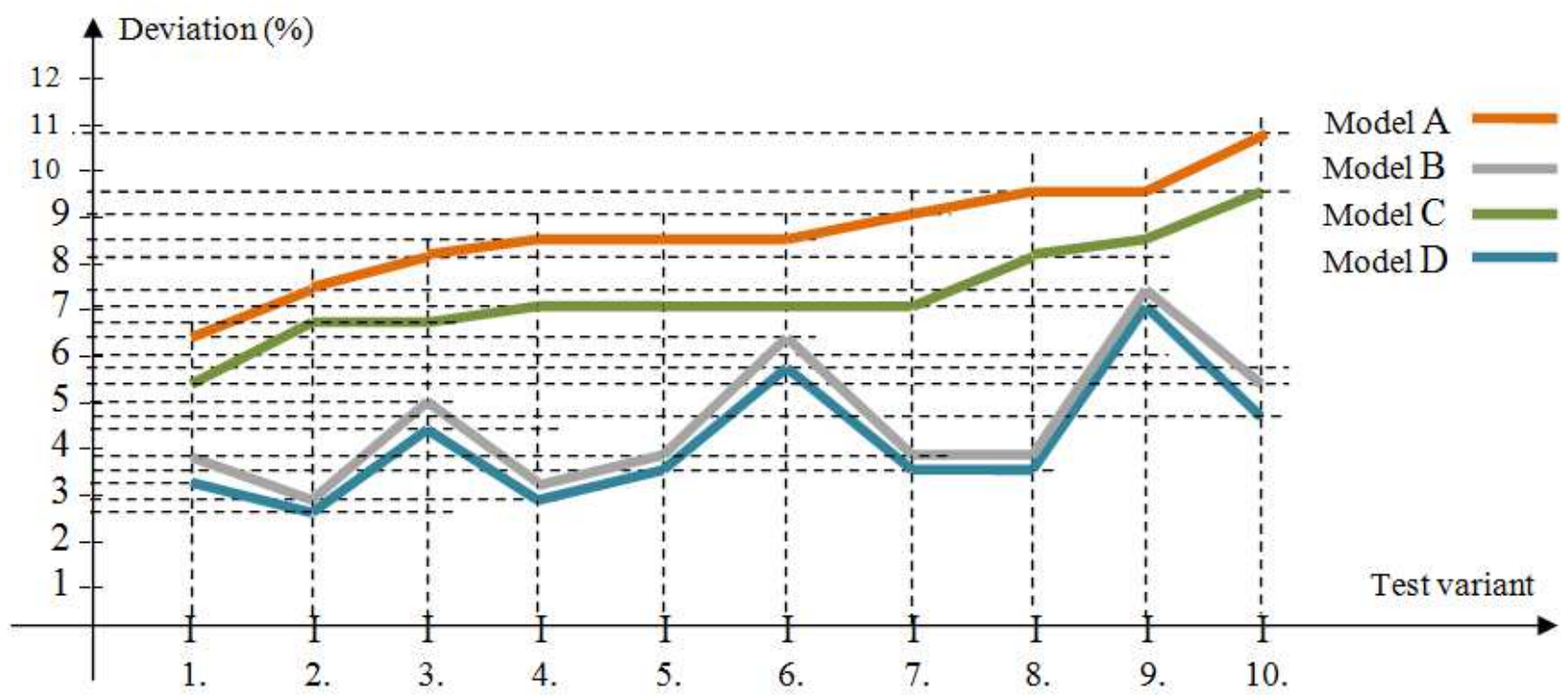

Figure 4. Graphical presentation of optimization models testing for the example of automotive glass production. (B. Gordic, 2013)

It can be seen from the above given that the differences in the profits realized according to the considered models are almost negligible so it can be concluded that the corrections of the plans were made with almost no losses. This at the same time proves that with corrective, adaptive optimization of production it is possible to achieve a satisfactory optimum, with maximum adjustment to changes and disturbances in the environment.

It is evident that the best results were acheved by applying discrete corrective dynamizing programming (model D) and that very good results were also achieved by dynamizing linear programming based on flexible, sliding planning and control without corrective optimization (model B). This at the same time confirms that in addition to the programming method, another very important factor is the way the process planning and production control is done.

Observing the test variants in sequence it can be seen that in the case of model A the deviation in quantity is constantly increasing, which in the testing variant means a higher percentage of expected and unexpected additional orders. Similar change in the results can be observed also in model $\mathrm{C}$, however, the deviation in quantity is smaller.

Different trend in optimization results can be observed in models B and D, as it is shown in Figure 2, because in these models due to flexible planning the plans are being constantly adjusted to changes in the environment. Better results were obtained when there was a greater share of expected additional orders, i.e. those orders that were timely included in the plans by flexible planning, with significantly smaller deviations in quantity, which at the same time 
indicates adaptability to changes.

It is evident that it is very important to be timely provided with sufficient number of reliable input information for preparation of operational plans so that the difference between the lower and upper limits of demand might be as low as possible. It is also important that the production system is as flexible and adaptable as possible so that the additional and extraordinary orders might be included to the greatest possible extent and in the most efficient way into the actual operational production plans.

Testing of the models was performed in a simplified way and with a small number of products and related data which was a sort of limitation in this study. With more narrow limits of demand in the variant of classical linear programming the deviation per products between the planned and the realized quantities shown in Table 3 . would be smaller. It is also realistic that then in the variant of linear programming with corrective optimization by simulation there would be more corrections and thus the differences between the planned and the realized quantities would be smaller, however, the costs would be higher.

\section{Conclusion}

According to the obtained test results it can be stated that the model of discrete corrective dynamizing optimization in preparation of optimal production plans is the model that provides considerable adjustment of production to the changes in the environment and in the production system itself, including timely changes concerning the resources necessary for production.

The possible variants of plans correction, in the function of adjustment to changes, involve those solutions for which the necessary resources already exist or can be readily provided and with which the launching of new orders in production will be performed with possible changes of the place or term of works for the already launched work orders, however, only within their given deadlines.

It can be also concluded that this model of flexible operational planning and production control, as well as other optimization models in the conditions of uncertainty-change, will not always provide solutions with the maximum results according to the selected criteria. But it will certainly enable the production system to get adjusted to changes and objective situations with the least deviation from the initial solutions, i.e. from maximally possible results, in a better and easier way than in the case when known similar models are applied.

The considered tests were performed for the cases when there was even up to $70 \%$ of expected and unexpected additional orders, with different relations of these groups of orders. They have shown that it is most favourable to use the model of discrete corrective dynamizing programming (D) as well as the model of dynamizing linear programming (B) in the following cases:

1. In the combined make-to-order and make-to-stock batch production
2. In the case of larger percentage of additional orders with the deadlines that may be included in the corrections of the initial plans by using flexible planning and control

3 . In the cases when the share of expected and unexpected additional orders is approximately equal

It is important to note here that similar results would be obtained when the testing of the models would include negative changes, i.e. disturbances in the production- delays due to breakdowns, lack of materials, and lack of energy, cancellation of orders, etc. Then corrections would be made with a reversed sign and the initial operational plan would have a more low demand lower limit and considerably lower upper demand limit, in line with the available resaurces for production.

In the papers which provide overview and analysis of research in the field of production planning and control [12] there is insufficient research and solutions which could more closely connect the existing models of production planning and control with actual processes and needs. This is particularly related to cases in practice when instability and intense changes in the environment are present. A review of research in theories of planning and scheduling in the 20th century for various problems and possible approaches [13] shows that the iterative process of planning and scheduling should be a continuation of existing examples in solving of practical problems of planning and scheduling.

The theoretical consideration of this problem needs to take into account that when the application of mathematical methods and optimization techniques, always adapts the reality to the mathematical model, to a bigger or lesser extent. The result is that a set of optimal solutions-possibilities $S_{o}$ contains not only elements from a set of options $S_{i}$ but the parts outside of this set, too. As a consequence, a discrepancy between the optimal elements specified by mathematical programming and real quantity of elements of optimization occurs. Therefore, the practice shows that, e.g. there is a deficit of certain product in an optimal production program for some period, and on the other hand, a surplus of some products in relation to the real demand. These discrepancies are bigger as there are more unstable conditions in the environment, as it demonstrated by this study. These can be reduced and adapted to the system of changes in the environment, only with more frequent adjustment of production plans with optimization by using the method of simulation.

Further research of the process of adaptable production planning and control are possible in the direction of establishing the various methods and models to optimize the structure of production and business systems in function of flexibility and adaptation in terms of uncertainty and changes. Such subsequent research should determine how to structure the production system and run a manufacturing process that would be optimally flexible and adaptable according to selected criteria. This particularly refers to a tighter linking between production planning and control and processes of enterprise management, and in this context a better connection with the processes of sales, purchasing, 
production, and beyond.

Possible variants of the method of election of the procedures for determining and development of the planning and control process in the function of production and business management, should also be the subject of further research. This direction of further research is closely related to the previously mentioned because it is important to optimize the structure and processes of the production system if the goal is to achieve greater optimality, flexibility and adaptability.

In any case, it is to be expected that further interest will ignite new needs for research of production planning and control in terms of uncertainty and changes, and other specific conditions for various forms of production.

\section{References}

[1] C.A.Soman; D.P.Van Donk; G.J.C.Gaalman, "Capacitated Planning and Scheduling for Combined Make-to-order and Make-to-stock Production in Food Industry", International Journal of Production Economics, Vol.108, pages 191-199, 2007.

[2] L.C.Hendry; B.G.Kingsman, "Production Planning System and Their Applicability to Make-to-order Companies", European Journal of Operational Research, Vol.40, pages 1-15, 1989.

[3] J.Olhanger; M.Rudberg; J.Vikner, "Long-term Capacity Management: Linking the Perspectives for Manufacturing Strategy and Sales and Operations Planning", International Journal of Production Economics, Vol.69, pages 215-225, 2001.

[4] P. G. Moscoso, J. C. Fransoo, D. Fisher, "An Empirical Study on Reducing Planning Instability in Hierarchical Planning System", Production Planning \& Control Journal, 4/2010, pages $413-426$
[5] G. C. Kim, M. J. Schniederjans, S. S. Kim, "Simulation Study of Availability Management in a Make-to-order Manufacturing Environment for a Differentiated Order System", Production Planning \& Control Journal, 1/2010, pages $47-49$

[6] H. Stefansson, P. Jensson, N. Shah, "Procedure for Reducing the Risk of Delayed Deliveries in Make-to-order Production", Production Planning \& Control Journal, 4/2009, pages 332342

[7] J. E. Hernandez, J. Mula, F. J. Ferriols, "A Reference Model for Conceptual Modelling of Production Planning Processes", Production Planning \& Control Journal, 8/2008, pages 725734

[8] M. M. Al Durgham, M. A. Barghash, "A Generalised Framework for Simulation-based Decision Support for Manufacturing", Production Planning \& Control Journal, 5/2008, pages $518-534$

[9] T. Taskinen, "Improving Change Management Capabilities in Manufacturing: From Theory to Practice", Production Planning \& Control Journal, 2/2003, pages 201-211

[10] S. Mestry, P. Damodaran, Chin-Sheng Chen, "A Branch and Price Solution Approach for Order Acceptance and Capacity Planning in Make-to-order Operations", European Journal of Operational Research, Vol.211/2011, pages 480-495

[11] T. Volling, T. S. Spengler, "Modeling and Simulation of Order-driven Planning Policies in Build-to-order Automobile Production", International Journal of Production Economics, Vol.131/2011, pages 183-193

[12] J. Mula, R. Poler; J. P. García-Sabater; F.C. Lario, "Models for Production Planning under Uncertainty: A Review", International Journal of Production Economics, Vol.103/2006, pages $271-285$

[13] J. N. D. Gupta, "An Excursion in Scheduling Theory: An Overwiew of Scheduling Research in the Twentieth Century",Production Planning \& Control Journal, 2/2002, pages $105-116$ 